\title{
Home Automation Using Cloud Computing and Mobile Devices.
}

\author{
Prof. M. B. Salunke, Darshan Sonar, Nilesh Dengle, Sachin Kangude, \\ Dattatraya Gawade \\ Sinhgad Institute of technology \& sciences, Narhe, pune 41.
}

\begin{abstract}
Today, we are entering post-PC era where mobile devices (e.g. Smartphone's, Smartphone's and Handheld tablets) are handling daily tasks that traditional desktop and laptop computers once handled. Several reports show that personal computers are no longer on the leading the edge of computing and the use of mobile devices are quickly taking over. Accompanying the shift from PCs to multi-touch mobile devices is the use and implementation of Cloud Networking. With the availability of products which integrate mobile devices and cloud networking rapidly increasing, many users can see how new technology can impact their everyday lives. In this paper we have developed a Home Automation system that employs the integration of multi-touch mobile devices, cloud networking, wireless communication, and power-line communication to provide the user with remote control of various lights and appliances within their home. This system uses a consolidation of a mobile phone application, handheld wireless remote, and PC based program to provide a means of user interface to the consumer. The home automation system differs from other systems by allowing the user to operate the system without the dependency of a mobile carrier or Internet connection via the in-home wireless remote. This system is designed to be low cost and expandable allowing a variety of devices to be controlled.
\end{abstract}

\section{INTRODUCTION}

Modern advances in electronics and communications Technologies have lead to the miniaturization and improvement of the performance of computers, sensors and networking. These changes have given rise to the development of several home automation technologies and systems. According to, home automation can be useful to those who need to Access home appliances while away from their home and can incredibly improve the lives of the disabled. Many of the home automation systems that are commercially available can be separated into two categories: locally controlled systems and remotely controlled systems. Locally controlled systems use an in-home controller to achieve home automation. This allows users complete use of their automation system from within their home via a stationary or wireless interface. Remotely controlled systems use an Internet connection or integration with an existing home security system to allow the user completes control of their system from their mobile device, personal computer, or via telephone from their home security provider. There are a number of issues involved when designing a home automation system. Piyare and Tazil [4] discussed that the system should be scalable so that new devices can easily be integrated into it. It should also provide a user- friendly interface on the host side, so that the devices can be easily setup, monitored, and controlled. Furthermore the overall system should be swift enough to realize the true power of wireless technology. Lastly the system should be cost

Effective in order to justify its application in home Automation. To minimize the shortcomings of each system and to overcome the design issues previously mentioned, this project integrates locally and remotely controlled systems with the use of Cloud data network. This allows the system to operate without the dependence of a mobile provider, allows the system to be used with various mobile phone platforms, and allows the system to operate locally when phone or computer access is not available. Cloud networking and data infrastructure allow individuals to monitor, manage, and control their personal data points through the Internet. Each data stream is given a unique feed identification number to differentiate itself from all other data Streams on the Network. This paper will discuss the Development of a home automation system, as illustrated in .In home control is achieved via a hand held remote which uses Zigbee wireless communication to the in home controller which is integrated with the cloud network via an internet connection.

\section{RESULTS}

The project was completed and is working as described in this paper. The system allows the user to control appliances and lights in their home from a smart phones and PC from anywhere in the world through an internet connection. It also allows the user to control their units within their home from a wireless remote. The wireless remote has primary control over the system; therefore if the remote is active neither the Smartphone nor PC will be able to control the units in the home. This design prevents from the Smartphone, PC, and wireless remote all trying to control the system at the same time. The project was tested to turn appliances on and off such as: radio, fan, coffee maker, and television. It also was tested to brighten and dim various light structures. 
The system refreshes on the Smartphone and PC every time the user chooses an option to control or monitor a specific unit.

\section{DIAGRAM:-}

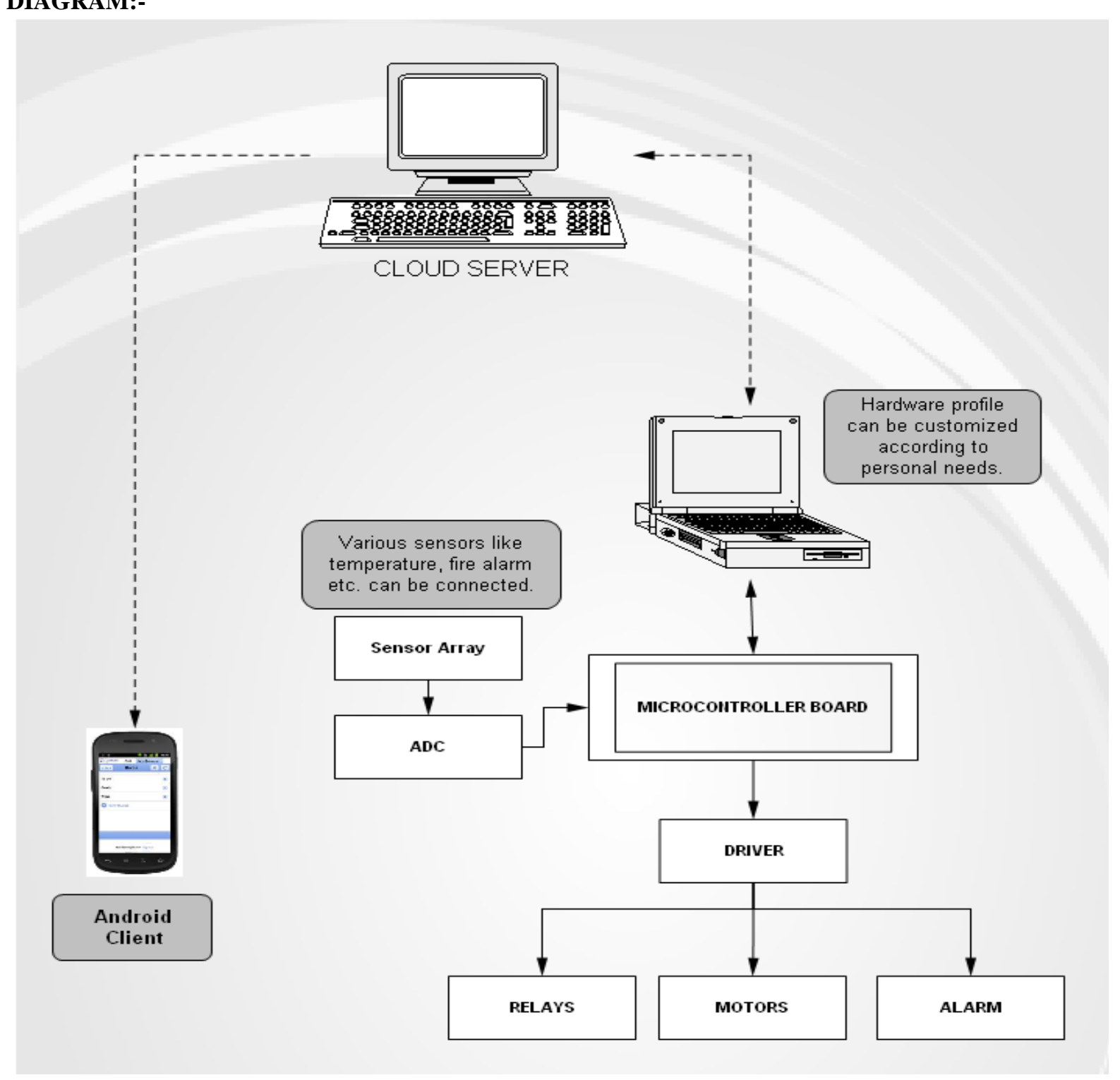

Home Automation is the residential extension of "building automation". It is automation of the home, housework or household activity. Home automation may include centralized control of lighting, heating, ventilation and air conditioning, appliances, and other systems, to provide improved convenience, comfort, energy efficiency and security.

A home automation system integrates electrical devices in a house with each other. The techniques employed in home automation include those in building automation as well as the control of domestic activities, such as TV, fan, electric tubes, refrigerator and washing machine

The system allows the user to control appliances and lights in their home from an android and PC from anywhere in the world through an internet connection. It also allows the user to control their units within their home from a wireless remote. The wireless remote has primary control over the system; therefore if the remote is active neither the android nor PC will be able to control the units in the home. This design prevents from the android, PC, and wireless remote all trying to control the system at the same time. The project was tested to turn appliances on and off such as: radio, fan, coffee maker, and television. It also was tested to brighten and dim various light structures. The system refreshes on the Smartphone and PC every time the user chooses an option to control or monitor a specific unit. The in-home remote is updated on the LCD monitor every time the system receives a command. The project did run into a memory problem. After research, we found that the ATmega32Duemilanove's flash drive does not operate well with the ATmega32 Ethernet Shield 
connected. Therefore all the incoming data from had to be saved on the ATmega32 Duemilanove's EEPROM data storage. This posed a problem as the EEPROM only allows the user to rewrite over data for a certain number of times. An external ATmega32 flash drive is considered for the option for further work.

\section{REFERENCES}

[1] Chan, M., Campo, E., Esteve, D., Fourniols, J.Y., "Smart homes-current features and future perspectives," Maturitas, vol. 64, issue 2, pp. 90-97, 2009.

[2] Das, S.R., Chita, S., Peterson, N., Shirazi, B.A., Bhadkamkar, M., "Home automation and security for mobile devices," IEEE PERCOM Workshops, pp. 141-146, 2011.

[3] Laur, I., "Microcontroller based home automation system with security," International Journal of Advanced Computer Science and Applications, vol. 1, no. 6, pp. 60-65, 2010.

[4] Piyare, R., Tazil, M., "Bluetooth based home automation system using cell phone," IEEE ISCE, pp. 192195, 2011.

[5] "Glassfish Info" http://glassfish.java.net/

[6] Communication of mobile and tablet devices" http://www.arkessa.com

[7] ATmega32" http://www.atmel.com/devices/atmega32.aspx

[8] ULNDarlingtondriver" http://www.onsemi.com/PowerSolutions/product.do?id=ULN2003

[9] Gomez, C., Para dells, J.," Wireless home automation networks: A survey of architectures and technologies," IEEE Communications Magazine, vol. 48, issue 6, pp. 92 - 101, 2010. 